\title{
Prevalence of Self-Medication among Urban and Rural Population of Islamabad, Pakistan
}

\author{
T Aqeel $^{1}$, A Shabbir $^{2,3^{*}}$, H Basharat ${ }^{1}$, M Bukhari $^{1}$, S Mobin ${ }^{1}$, H Shahid $^{1}$ and SA \\ Waqar $^{4}$ \\ ${ }^{1}$ School of Pharmacy, The University of Lahore-Islamabad Campus, Islamabad, ${ }^{2}$ Department of Pharmacology, University of \\ Health Sciences, Lahore, ${ }^{3}$ Lahore Pharmacy College, Lahore, ${ }^{4}$ Wah Medical College, Wah Cantt, Pakistan
}

*For correspondence: Email: charham007@hotmail.com; Tel: +923136220766

Revised accepted: 15 February 2014

\begin{abstract}
Purpose: To evaluate the prevalence and associated factors of self-medication among urban and rural population of Islamabad, Pakistan.

Methods: A cross-sectional study was conducted among 500 participants using random sampling method. A pretested questionnaire was used to collect the data from urban and rural areas of Islamabad. Chi square/Fisher's exact test was used to compare two groups.

Results: Overall, $61.2 \%$ of participants practised self-medication and it was more prevalent among $15-$ 30 years age group. An association was found between self-medication and residence, gender, and education ( $p$ <.05). A majority of participants $(n=364,72.8 \%)$ trusted Allopathic system the most. Pain was the most likely indication $(n=207,67.6 \%)$ for which participants self-medicated $(p<0.05)$. Analgesics were the most likely ( $n=187,61.1 \%)$ medicine class used ( $p<0.05)$, majorly, paracetamol. Mild illness ( $n=128,41.8 \%$ ) was determined as the most common reason $(p<0.05)$. Generally, higher proportion of urban participants reported "previous experience" and "time saving" as the most common reason for the practice of self-medication in contrast to "economical" and "lack of health care facilities" described by rural participants. A majority of the participants ( $n=186,60.8 \%)$ self-medicated on their own initiative $(p<0.001)$. Generally, higher percentage of urban participants reported family/friends $(27.9 \%$ versus $15.7 \%)$ as the commonest source in contrast to medical professionals $(21.6 \%$ versus $5.2 \%)$ reported by rural respondents.

Conclusion: This study shows an association between self-medication and gender, residence, and education. Urban and rural participants significantly differ on the most common reason, symptom, source and class of drug used for self-medication.
\end{abstract}

Keywords: Self medication, Prevalence, Rural, Urban, Analgesics

Tropical Journal of Pharmaceutical Research is indexed by Science Citation Index (SciSearch), Scopus, International Pharmaceutical Abstract, Chemical Abstracts, Embase, Index Copernicus, EBSCO, African Index Medicus, JournalSeek, Journal Citation Reports/Science Edition, Directory of Open Access Journals (DOAJ), African Journal Online, Bioline International, Open-J-Gate and Pharmacy Abstracts

\section{INTRODUCTION}

The concept of self-medication has gained universal acceptance as it encourages an individual to treat minor illness with effective and simple remedies [1]. It is even promoted so as to have self-belief in preventive, curative and rehabilitative care [2]. According to world selfmedication industry, it is one of the most essential tools used by a person suffering from a common illness, which does not necessitate doctor's visit. It is usually considered as first choice remedy for early disease symptoms and is a part of patient's medical behavior [3].

Self-medication can potentially do well and also harm people. This is especially significant in those countries where prescription drugs are 
available over-the-counter (OTC) due to lack of enforcement of regulations [4]. An amplified risk of worsening of existing illness pathology as well as risk of interactions between prescription medicine and hidden active ingredients of OTC drugs are always present with self-medication [5]. Improper practice of self-medication due to deficiency in knowledge can lead to side effects especially in physiological conditions like lactation and pregnancy, and in extreme ages, such as children and old age people $[6,7]$. In Pakistan, prescription only medicines are available without physician's prescription as OTC, which magnifies all problems, associated with the OTC drugs [8].

The prevalence of self-medication among urban and rural population of Islamabad, capital city of Pakistan has not been widely studied. The objective of the present study was to determine the prevalence and associated factors of selfmedication among urban and rural population of Islamabad, Pakistan.

\section{METHODS}

\section{Study setting}

Islamabad is the capital city of Pakistan and is situated at the foot of the Margala Hills. According to data from Capital Development Authority, Government of Pakistan, the city has a total area of $906.50 \mathrm{~km}^{2}$, which includes 220.15 $\mathrm{km}^{2}$ of urban area and $466.20 \mathrm{~km}^{2}$ of rural area. The population of the city is approximately 1.15 million which includes huge foreign/expatriate population [21,22]. The present work is a crosssectional study and was carried out among general population of urban and rural areas of Islamabad. Humak, Rawat, Sihala, Gangota, and Java were selected representing rural areas, whereas, Blue area and various sectors of Islamabad city were selected to represent urban areas.

\section{Study design}

A total of 500 participants were randomly included in the study from urban and rural population, 252 and 248 participants, respectively, during 2012. Citizens migrated from other cities of Pakistan and people of extreme age groups (<15 and >45) were excluded from the study. Medical professionals (doctors, pharmacists, and paramedical staff) and any person who were not willing to participate in the study were also not included. Respondents with emotional, psychiatric, and intellectual disturbances were excluded because these conditions could affect the reliability of their response.

Stratified random sampling technique was used to collect the data. A structured questionnaire was developed after extensive literature review. Prevalence of self-medication was evaluated by using a table containing six questions and participants were asked to fill the table in case of imaginary illness. Two likert scale test was used to analyze that either participants would most likely go for self-medication or consult a health care professional. First three questions were strong predictors of self-medication while last three were pointing that participant was aware of risks of self-medication so he/she would consult health care personnel. Questionnaire was tested in a pilot study including 10 respondents and amended accordingly. Prior to answering questions, participants were briefed on the intentions of the study, and after answering questions, participants were informally counseled regarding potential harmful effects of selfmedication. Illiterate participants were assisted by pharmacy students who collected the data, and all the medical terminologies were explained to them. Any use of OTC or prescription medicines without first consulting a doctor was considered as self-medication [4].

\section{Statistical analysis}

Data were analyzed by using PASW statistics version 18 software and presented as frequency, percentage, graph, and inferential statistics using Chi Square test/Fisher's Exact test. $p<0.05$ was considered as statistically significant.

\section{RESULTS}

A total of 500 people participated in the study. $252(50.4 \%)$ of the total participants were residing in urban areas, while 248 (49.6\%) resided in rural areas. Out of urban participants, 132 (52.38\%) were males, while 120 (47.62\%) were females. Out of rural respondents, 118 $(47.58 \%)$ were males, while $130(52.42 \%)$ were females. 300 participants were aged between 15 to 30 years, and ages of 200 participants were between the ranges of 31 to 45 years. Out of total respondents, $183(36.6 \%)$ were illiterate, and $317(63.4 \%)$ were literate.

Majority of the respondents ( $n=306$ : $61.2 \%$ ) were involved in self-medication, whereas, 194 $(38.8 \%)$ negated the practice of self-medication. We found out an association between practice of self-medication and residence, gender, and 
education when analyzed through Chi Square/Fisher's exact tests. Residents of urban areas were more likely to self-medicate $(p=$ $0.001)$ as compared to rural population. Generally, prevalence of self-medication among participants from urban areas was found as ( $\mathrm{n}=$ $172,68.3 \%)$ as compared to $(n=134,54 \%)$ in rural areas. Male respondents were more likely to self-medicate $(p<0.05)$ compared to female participants. Generally, $165(66 \%)$ of total male respondents used self-medication, while 141 $(56.4 \%)$ of total female respondents reported the practice of self-medication. No statistically significant difference was found in the practice of self-medication among participants of different age groups. Generally, 189 (63\%) respondents who aged between 15-30 years practiced selfmedication as compared to 117 (58.5\%) participants aging between 31 - 45 years. Literate participants were found more likely $(p<0.001)$ to self-medicate as compared to illiterate participants. 264 (83.3\%) literate participants reported the practice of selfmedication as compared to $42(23 \%)$ illiterate respondents. Table 1 shows the association between participant's characteristics and selfmedication.

Table 1: Association between participants' characteristics and self-medication

\begin{tabular}{|c|c|c|c|}
\hline $\begin{array}{l}\text { Participant } \\
\text { characteristics }\end{array}$ & $\begin{array}{l}\text { Self- } \\
\text { medication } \\
(n=306)\end{array}$ & $\begin{array}{l}\text { No self } \\
\text { medication } \\
(n=194)\end{array}$ & $p$-value \\
\hline \multicolumn{4}{|l|}{ Residence } \\
\hline Urban & $172(68.3 \%)$ & $80(31.7 \%)$ & $<0.05$ \\
\hline Rural & $134(54 \%)$ & $114(46 \%)$ & \\
\hline Gender & & & \\
\hline Male & 165 (66 \%) & $85(34 \%)$ & $<0.05$ \\
\hline Female & $141(56.4 \%)$ & $109(43.6 \%)$ & \\
\hline Education & & & \\
\hline Literate & $264(83.3 \%)$ & $53(16.7 \%)$ & $<0.001$ \\
\hline Illiterate & $42(23 \%)$ & $141(77 \%)$ & \\
\hline $\begin{array}{l}\text { Age } \\
15-30 \text { years } \\
31-45 \text { years }\end{array}$ & $\begin{array}{l}189(63 \%) \\
117(58.5 \%)\end{array}$ & $\begin{array}{l}111(37 \%) \\
83(41.5 \%)\end{array}$ & \\
\hline
\end{tabular}

No statistically significant difference $(p>0.05)$ was found among people living in urban and rural areas for the choice of most trusted medication system. Most of the people $(n=364,72.8 \%)$ trusted in allopathic medication system, followed by Homeopathic ( $n=76,15.2 \%)$, Herbal $(n=43$, $8.6 \%)$, and Unani $(n=17,3.4 \%)$ systems of medication, as shown in Figure 1. Among participants from urban and rural areas who practiced self-medicated, Pain $(n=207,67.6 \%)$ was found as most likely disease symptom for which self-medication was done $(p<0.05)$, followed by respiratory diseases $(n=44,14.4 \%)$, and allergy $(\mathrm{n}=37$ : 12.1\%). Other illness symptoms for which participants reported selfmedication were GIT diseases $(n=16,5.2 \%)$ and sleeping disturbances $(n=2,0.7 \%)$, as shown in Figure 2.

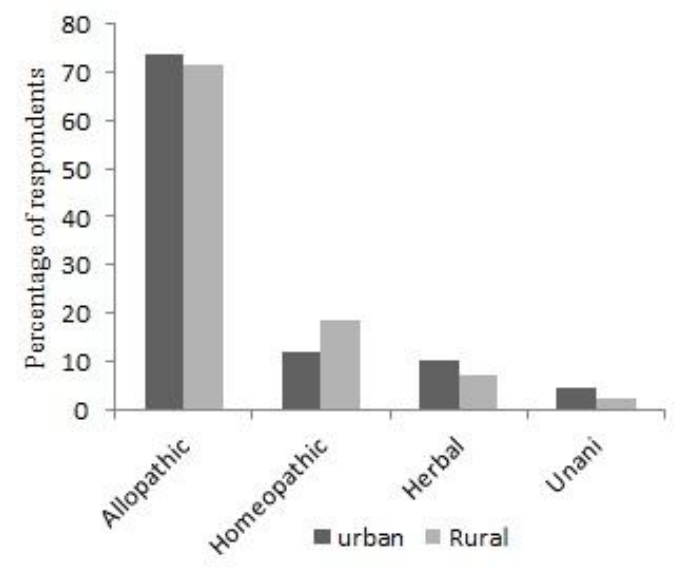

Figure 1: Most trusted medication system

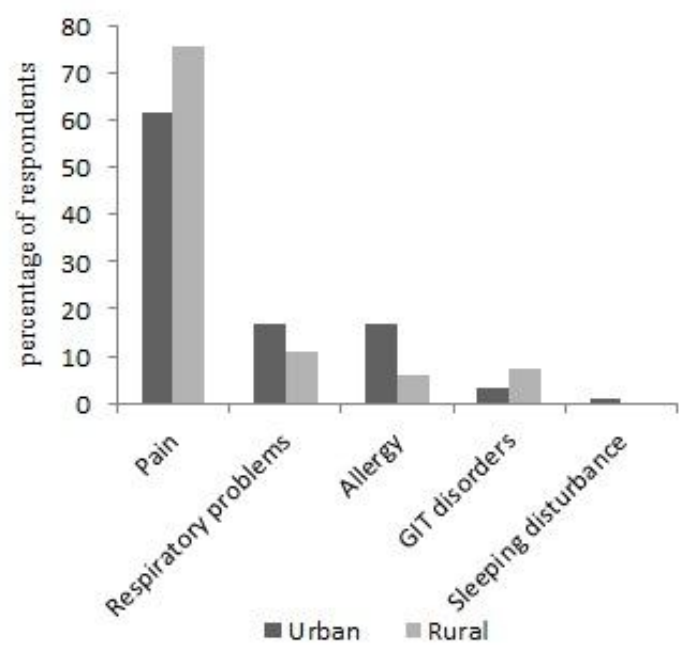

Figure 2: Indications for self-medication

Analgesics ( $n=187,61.1 \%)$ were determined as the most likely group of medicines used for selfmedication among urban and rural respondents $(p<0.05)$, who admitted practicing selfmedication. Analgesics were followed by antibiotics ( $n=42,13.7 \%)$, anti-allergics $(n=37$, $12.1 \%)$, multivitamins $(n=22,7.2 \%)$, drugs used in GIT disorders ( $\mathrm{n}=16,5.2 \%$ ), and sleeping pills $(n=2,0.7 \%)$, as shown in Figure 3. Among those respondents, who reported analgesics as the most common group of drugs used for selfmedication, majority ( $\mathrm{n}=80,42.8 \%)$ used Paracetamol. No statistically significant difference was found in the use different type of analgesic drugs among urban and rural population. Other analgesic drugs used for selfmedication were mefenamic acid $(n=49$ : 
$26.2 \%)$, aspirin ( $n=30,16 \%)$, ibuprofen $(n=18$, $9.6 \%)$, diclofenac $(n=6,3.2 \%)$, naproxen $(n=2$, $1.1 \%)$, and flurbiprofen $(n=2,1.1 \%)$, as shown in Figure 4.

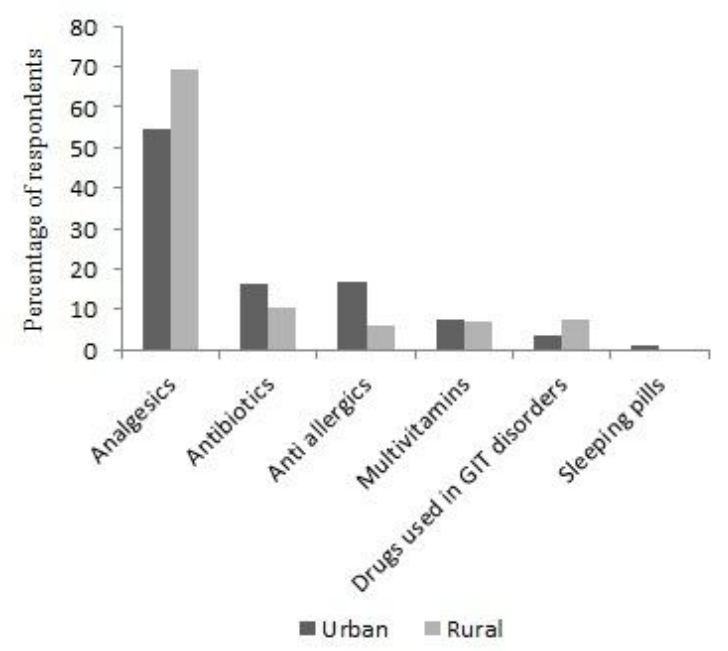

Figure 3: Classes of drugs used for self-medication

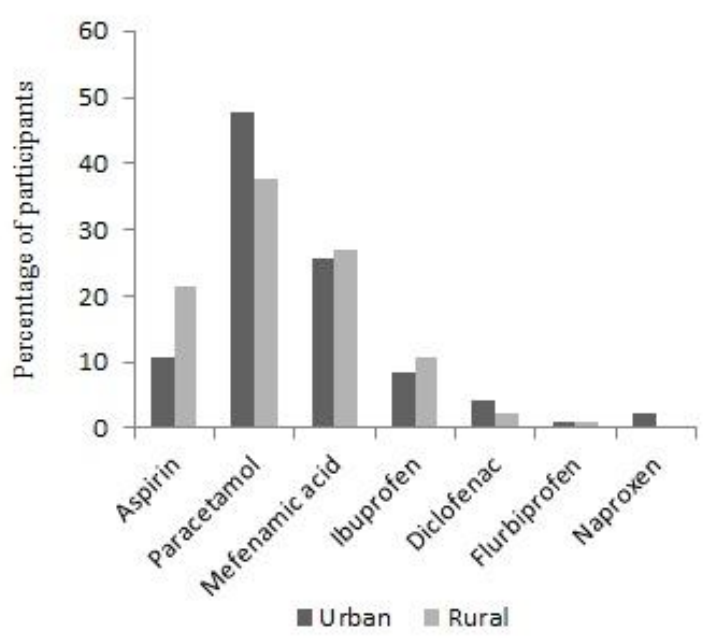

Figure 4: Different analgesic drugs used for selfmedication

When the most common reason for the practice of self-medication was analyzed, a significant difference was found among urban and rural sectors $(p<0.05)$. A majority of the total participants $(n=128,41.8 \%)$ reported "mild illness" as the most common reason, followed by "economical" $(\mathrm{n}=65,21.2 \%)$, "previous experience" ( $n=60,19.6 \%)$, "time saving" $(n=$ $23,7.5 \%)$, "lack of health care facilities" $(n=22$, $7.2 \%)$, and "enough knowledge" $(n=8,2.6 \%)$. Generally, a higher proportion of participants from urban sector reported "previous experience" and "time saving" as the most common reasons as compared to rural sector. On the other hand, a higher proportion of participants from rural sector reported "economical" and "lack of health care facilities" as the most common reasons, as compared to urban participants (Figure 5).

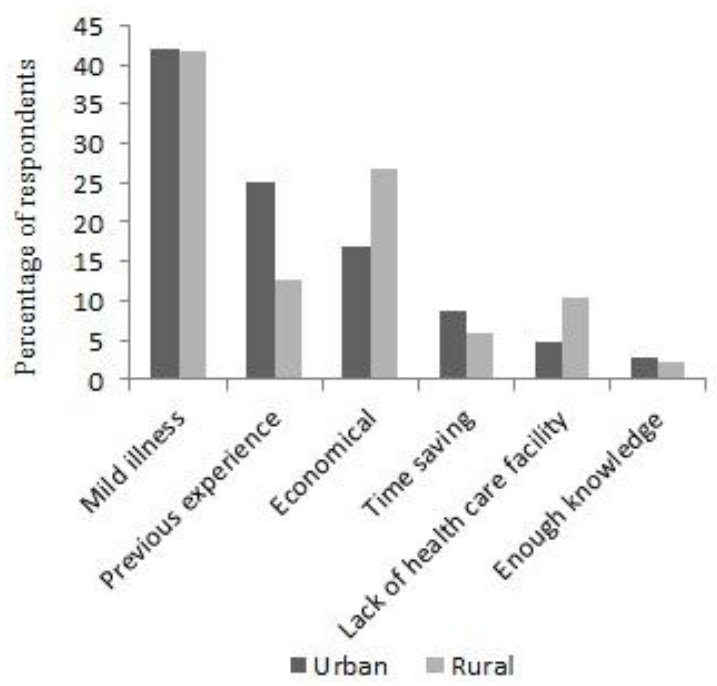

Figure 5: Reasons for self-medication

When the most common sources of information on self-medication were determined, highly significant difference was observed among urban and rural population $(p<0.001)$. This survey showed that majority of the participants $(n=186$, $60.8 \%$ ) practiced self-medication on their own initiative. Other most common sources of information on self-medication were family/friends $(\mathrm{n}=69,22.5 \%)$, healthcare professionals $(n=38,12.4 \%)$, and sales clerk at medical store $(n=13,4.2 \%)$, as shown in Figure 6. Generally, higher percentage of urban participants reported family/friends $(27.9 \%)$ as the most common sources of information on selfmedication compared to rural participants $(15.7 \%)$. On the other hand, a higher proportion of rural participants described medical professionals $(21.6 \%)$ as the most common source of information on self-medication compared to urban participants (5.2\%).

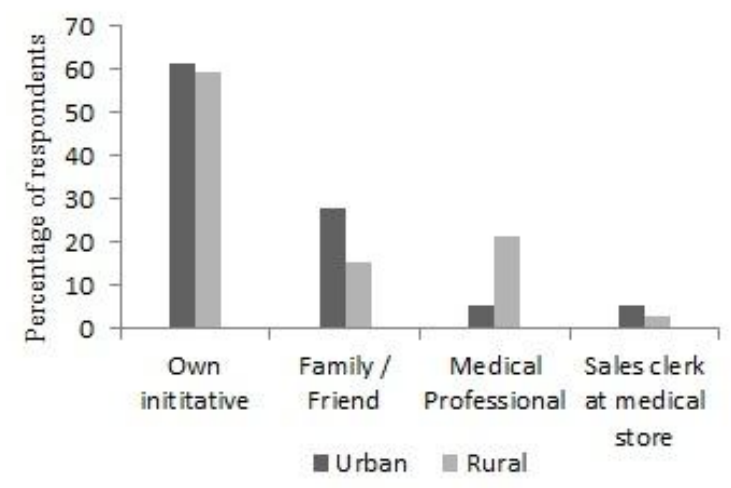

Figure 6: Sources of information on self-medication 


\section{DISCUSSION}

In Pakistan, almost every pharmacy would sale a drug to customer without seeking prescription as in the case of many other developing countries [9]. This phenomenon along with extensive advertising of medicines by pharmaceutical companies encourages the lay man to indulge in self-medication [10].

In present study, prevalence of self-medication was evaluated among general population of urban and rural areas of Islamabad, Pakistan. Our results showed $61.2 \%$ prevalence rate in Islamabad population, which is very similar to a study conducted in Faisalabad, Pakistan [11]. It is higher than Hong Kong China (32.5\%) [12], while lower than Slovenia (92.3\%) [3]. Regional, educational, socio-cultural conditions, and different methodologies used for determining self-medication may be among the reasons for the wide variations among these studies. The present study revealed higher prevalence rate in urban areas than rural areas of Islamabad, which is in line with the study conducted in India [13], however, in Sri Lanka, the prevalence rate in rural areas was higher than in urban areas [14]. It is not unexpected that due to the unsatisfactory medical care, people with busy urban lifestyle use self-medication as an alternative especially in mild illnesses. On the other hand, the likelihood of self-medication is lower in rural areas due to less affordability of health care [14]. This survey showed a higher prevalence rate in males than females which is in agreement with the findings of previous studies conducted in Portugal [15] and Faisalabad [11]. Males are economically stronger, can easily access medical store, and freely move outside. More dependency on males than females in our society may be a reason for the relatively low self-medication level seen in females [11]. Although there was statistically insignificant difference among different age groups in the use of self-medicate, however, generally a higher portion of young participants indulged in selfmedication. Another study also showed decreasing pattern of self-medication with increase in age [16]. This can be explained by the fact that as a person gets older, he or she starts visiting doctor more frequently [11].

The present survey revealed a high likelihood of self-medication in literate participants compared to illiterate participants. Other studies in Nigeria showed the influence of education on selfmedication practice $[1,17]$. Educated people can clearly read and understand the labels of consumed medicines, while illiterate people find it almost impossible to read and understand labels. Illiterate people usually opt for easier to remember ways of recognizing medicines, e.g., common usage names and colors of medicines [1]. The ability of educated people to read and understand labels of the consumed medicine makes them more prone to self-medication as compare to illiterate people.

A majority of the participants in our study reported Allopathic system as the most trusted medicine system. This is in line with results of previous study conducted in South Indian city [16]. Participants also showed their trust in homeopathic, Herbal and Unani system. The general population of India perceives homeopathy and ayurvedic medication systems as; their own system, based on natural constituents, time tested, very acceptable among children, and with lesser side effects [23]. This perception along with the common availability of these medicines in homes makes people susceptible to practicing self-medication. The present study found pain the most common disease symptom for which participants selfmedicated followed by respiratory diseases and allergy. Analgesics were the most common class of the drug which participants used for selfmedication followed by antibiotics and antiallergics. Paracetamol was reported as the most common analgesic drug used. This is similar to the study conducted in South India [16]. Mefenamic acid and Aspirin were other analgesic drugs reported by participants. Practice of selfmedication with analgesics is accepted and common. Health systems also recommend selfmedication with analgesics in order to avoid reimbursement [18]. Pain killers among others are the most commonly available OTC medicines. Excessive use of OTC medicines can cause serious adverse effects despite of their usefulness in treating common health illnesses [8].

The present survey showed that most common reason for which participants self-medicated were "mild illness". This is similar to the study conducted among medical students in South India [19]. "Mild illness" was followed by "previous experience" in our findings. Misplaced confidence can cause inappropriate selfmedication and respondents can be exposed to all risks associated with the practice of selfmedication [20]. A higher proportion of rural population reported "lack of health care facilities" and "economical" compared to urban population. Most of the rural areas of Pakistan do not have a sufficient number of dispensaries and in those villages where dispensaries are present; they are 
not properly functional due to lack of medical staff and unavailability of medicines. Many people living in rural areas of Islamabad rely on daily wage as they daily visit the city for their income. In this background, the high proportion of rural population self-medicating in our study for these reasons makes sense. On the other hand, residents of Islamabad city, a capital city of Pakistan, live a busy life. Higher number of urban participants self-medicating due to "time saving" than rural participants is logical.

Our findings showed that most of the people selfmedicated on their own initiative. Other most common sources of information on selfmedication include family/friends, medical professionals, and sales clerk at medical store. Involvement of such a high proportion of people in self-medication based on their own initiative underscores the need for health care providers to run an aggressive awareness campaign regarding the risks associated with selfmedication. Higher proportion of participants belonging to urban sector reported family/friends as the most common source of information compared to rural participants who indicated healthcare professionals. This may be due to the busy schedule of urban people who hardly find to visit their doctors. Thus, people residing in rural areas tend to spend their hard earned money in more effective and rational way in their healthcare seeking, meaning that they are more likely to consult a medical professional than spending money on self-medication unnecessarily [14].

\section{Limitations of the study}

One limitation of this study is the limited sample size used for this study, which we tried to overcome by use of a random sampling method so as to generalize findings. Other possible limitations such as the possibility that some of respondents might have not disclosed the truth, bias by the students who collected the data, and recall bias can possibly affected the findings of the study.

\section{CONCLUSION}

Urban and rural population significantly differed in the most common reason, source of information on, symptom and class of drug used for self-medication. An association was also found between self-medication and residence, gender, and education. High percentage of people practicing self-medication on their own requires initiation of an awareness campaign in
Pakistan by health care providers is required in view of the high proportion of the populace that indulge in self-medication. Pharmacist can and should play an important role in counseling the patients when dispensing drugs from outlet. Rules and regulation regarding sale of drugs from pharmacy outlets should be closely monitored by government authorities.

\section{REFERENCES}

1. Afolabi AO. Factors influencing the pattern of selfmedication in an adult Nigerian population. Ann Afr Med. 2008; 7 (3): 120-127.

2. Abosede OA. Self-medication an important aspect of primary health care. Soc Sci Med. 1984; 19: 699-703.

3. Klemenc-Ketiš Z, Hladnik Ž, Kersni J. A cross sectional study of sex differences in self-medication practices among university students in Slovenia. Coll Antropol. 2011; 35 (2): 329-334.

4. Sontakke SD, Bajait CS, Pimpalkhute SA, Jaiswal KM, Jaiswal SR. Comparative study of evaluation of selfmedication practices in first and third year medical students. Int J Biol Med Res. 2011; 2(2): 561-564.

5. Choonara I, Gill A, Nunn A. Drug toxicity and surveillance in children. Br J Clin Pharmacol. 1996; 42: 407-410.

6. Shankar PR, Partha P, Shenoy N. Self medication and non doctor prescription practices in Pokhara valley. Western Nepal: a questionnaire-based study. BMC Fam Pract. 2002; 17. http://www.biomedcentral.com/1471-2296/3/17.

7. Murray MD, Callahan CM. Improving medication use for older adults: An integrated research agenda. Ann Intern Med. 2003; 139: 2425-2429.

8. Hussain A, Khanum A. Self medication among university students of Islamabad, Pakistan - a Preliminary Study. Southern Med Rev. 2008; 1 (1): 14-16.

9. Chang FR, Trivedi PK. Economics of self-medication: theory and evidence. Health Econ. 2003; 12(9): 721739.

10. Loyola FAl, Lima-Costa MF, Uchoa E. Bambui Project: a qualitative approach to self-medication. Cad Saude Publica. 2004; 20(6): 1661-1669.

11. Baig S. Self medication practices. Prof Med J. 2012; 19(4): 513-521.

12. Lam CL, Catarivas MG, Munro C, Lauder IJ. Selfmedication among Hong Kong Chinese. Soc Sci Med. 1994; 39(12): 1641-1647.

13. Balamurugan E, Ganesh K. Prevalence and pattern of self medication use in coastal regions of South India. Br J Med Pract. 2011; 4(3): a428.

14. Wijesinghe $P R$, Jayakody $R L$, de $A$ Seneviratne $R$. Prevalence and predictors of self-medication in a selected urban and rural district of Sri Lanka. WHO. South-East. Asia. J Public Health. 2012; 1(1): 28-41.

15. Martins AP, Miranda Ada C, Mendes Z, Soares MA, Ferreira $P$, Nogueira $A$. Self-medication in a Portuguese urban population: a prevalence study. Pharmacoepidemiol. Drug. Saf. 2002; 11(5): 409414.

16. Kulkarni, PK. Khan M, Chandrasekhar, A. Self medication practices among urban slum dwellers in South Indian city. Int J Pharm Bio Sci. 2012; 3(3): 81-87.

17. Osemene KP, Lamikanra A. A Study of the Prevalence of Self-Medication Practice among University Students in Southwestern Nigeria. Trop J Pharm Res. 2012; 11(4): 683-689.

18. Fox JM. Use of analgesics in self-medication. Therapie. 2002; 57(2): 115-118.

19. Badiger S, Kundapur R, Jain A, Kumar A, Patanashetty $S$, Thakolkaran N, Bhat N, Ullal N. Selfmedication patterns among medical students in South India. 
Australasian Med J. 2012; 5 (4): 217 - 220.Lang HC, Lai MS, Chen GT. Outpatient drug expenditures and prescription policies for diseases with high cost to the National Health Insurance system in Taiwan. J Formos Med Assoc 2004; 103: 280-285.

20. James H, Handu SS, Khalid AJ, Khaja A, Otoom S, Sequeira RP. Evaluation of the knowledge, attitude and practice of self-medication among first-year medical students. Med Princ Pract. 2006; 15: $270-$ 275.
21. Capital Development Authority. Facts \& Statistics. Available at: www.cda.gov.pk/about_islamabad/ vitalstats.asp. Accessed on 30-09-2013.

22. Wikipedia, the free encyclopedia. Islamabad. Available at: http://en.wikipedia.org/wiki/lslamabad. Accessed on 30-09-2013.

23. Jawla S, Gupta AK, Singla R, Gupta V. General awareness and relative popularity of allopathic, ayurvedic and homeopathic systems. J Chem Pharm Res. 2009; 1(1): 105-112. 